\title{
Possibilities of Using Mindfulness Training in Professional Practice of Social Work ${ }^{1}$ Miroslav Kappl
}

\begin{abstract}
:
The paper deals with the possibilities of using mindfulness training in social work practice, specifically, in case work. In this context, mindfulness training is seen as a method of important competencies strengthening. These important competencies help clients to make necessary changes in their lives. The paper briefly summarises the history of using this method and describes some results of current neuroscience research which is devoted to this issue. It also deals with the application of mindfulness training in the field of social work with selected groups of clients. In conclusion, the text critically points out some controversial aspects of this method when working with clients.
\end{abstract}

Keywords: social work, methods of social work, mindfulness training, meditation

\section{Introduction}

The coming of neuroscience discourse into a wider range of helping professions has given further impetus to the development of their client work methodologies. It has also helped to recognise the phenomenon of mindfulness training in the field of social work. ${ }^{2}$ Although this method had been known to the professional public for decades (thanks to authors who had relied on some Eastern philosophical concepts ${ }^{3}$ in their practice), it was the results of neuroscience research in the brain ${ }^{4}$ that confirmed and popularised the effective impact of this exercise called 'meditation'. This specific exercise has been practised in various cultural circles since ancient times, probably even before. ${ }^{5}$

As soon as the neuroscience discourse began to focus on the topic of 'attention' (which was recognised as an important component of any learning and decision-making process), the importance of meditation was identified. It was considered a tool for the cultivation of a person's mind

1 The article was created with the support of the grant project SPEV 'Přínosy tréninku všímavé pozornosti' solved at the Institute of Social Work, Philosophical Faculty, The University of Hradec Králové (2016/2017).

2 Cf. Malcolm PAYNE, Modern Social Work Theory, Basingstoke: Palgrave Macmillan, 2014, pp. 167-168.

3 Cf. Jon KABAT-ZINN, Život samá pohroma: Jak čelit stresu, nemoci a bolesti pomocí moudrosti těla a mysli, Brno: Jan Melvil Publishing, 2016; Daniel GOLEMAN, Základy meditace: meditujicí mysl, Praha: Triton, 2001; Mirko FRÝBA, Umění žít štastně: Buddhova Abhidhamma v praxi meditace a zvládání života, Praha: Argo, 2003; Mirko FRÝBA, Psychologie zvládání života: Aplikace metody Abhidhamma, Brno: Albert, 2008.

4 Cf. Daniel GOlEMAN, Destruktivní emoce, Praha: Ikar, 2004; Daniel GOLEMAN, Pozornost, Brno: Jan Melvil Publishing, 2014; Daniel SIEGEL, Vnitřni nazírání, Praha: Triton, 2014.

5 Cf. Mircea ELIADE, Jóga. Nesmrtelnost a svoboda, Praha: Argo, 1999, pp. 240-264. 
regardless of his basic value orientations, the way he relates to the world. In neuroscience, meditation has been interpreted as mindfulness training. This training can be recommended in any situation where a person is encouraged to practise the desired actions necessary to achieve his goal but he lacks the competence to regulate his behaviour to a significant degree. ${ }^{6}$ It is clear that such situations very often occur in the everyday practice of social work with individuals, and it is quite understandable that some authors already suggest the integration of mindfulness training into the professional skills of social workers. ${ }^{7}$

Before mindfulness training becomes a standard part of the pool of methods and techniques that social workers use everyday in practice, it is necessary to understand the basic principles of this method and thus build its use in practice on a sufficient theoretical basis. Otherwise, the use of mindfulness training will miss the desired effect. Although these reflections are already in progress abroad, in the Czech environment this topic is rather outside the interest of the professional public. The aim of this paper is to present the conceptual basis of mindfulness training to the reader and to describe the most important suggestions for the usage of mindfulness training in social work so far, as well as the potential risks that may arise during the application of this practice. I believe that this text will give confidence to those who may be considering this method and who see some potential in it. I also hope that it can guide their first steps in practice.

\section{Mindfulness Training - Conceptual Starting Points}

At the most general level, mindfulness training is a practice of conscious attention. ${ }^{8}$ The aim is to strengthen an individual's ability to pay attention to the present situation in a specific way, i.e., he has to be focused and he should not make any assessment. ${ }^{9}$ This is a secular form of meditation in which practitioners do not pursue any chosen spiritual goals. Instead, they strive to strengthen some of their personal competencies which help them to manage and further improve their lives. These non-spiritual goals were already present in some meditation systems (especially in Buddhism) and inspired the first models of meditation in the practice of helping professions in the West. ${ }^{10}$ We can consider these ways of working with clients as the first examples of the use of mindfulness training in our cultural sphere. Some of their practices can be used within the framework of generally known methods of social work. At present, however, mindfulness training involves far more different techniques and procedures. Their core is the targeted development of the watchful attention of the practitioners. Some of these techniques are based on traditional Buddhist or yoga meditation methods, many others have been developed in recent decades in the practice of helping disciplines. The latter were mostly created as a combination of some forms of mindfulness exercise and various cognitive-behavioural techniques. Some of these procedures are narrowly targeted to specific groups of clients, some of them are more universal. It is usually possible to learn these techniques through various courses and workshops. One can also try a self-study approach and use didactically conceived monographs, CDs, or DVDs.

The aim of the following sub-chapters is to describe the gradual development of the theoretical foundations of this method which includes two periods: the initial stage of taking over some

6 Cf. PAYNE, Modern..., p. 167.

7 Cf. Steven F. HICK, Mindfulness and social work, Chicago: Lyceum Books, 2009; (c Yuk-Lin Renita WONG, Knowing Through Discomfort: A Mindfulness-based Critical Social Work Pedagogy (on-line), available at: http://wwwl.uwindsor.ca/criticalsocialwork/ knowing-through-discomfort-a-mindfulness-based-critical-social-work-pedagogy, cited $29^{\text {th }}$ September 2018.

9 Cf. KABAT-ZINN, Život samá pohroma..., p. 24.

10 Cf. KABAT-ZINN, Život samá pohroma...; FRÝBA, Psychologie zvládání života... 
elements of Buddhist psychology, and the subsequent stage of reflecting the results of neuroscientific brain research. The latter has opened up future possibilities for mindfulness training within the field of helping professions.

\subsection{Eastern Roots of Mindfulness Training}

Mindfulness training was originally based on the Eastern method of personal 'liberation' which has been referred to as meditation in Western civilization for decades. There are many types of meditation (for example, various types within Hindu Yoga, Chinese Taoism, Hinayana and Mahayana Buddhism). However, the creators of the secular forms of mindfulness training were mainly inspired by those techniques which are fundamentally focused on mindfulness practice. During such practice, the practitioners have to concentrate on a single object (e.g., mantra, prayer, symbol, bodily sensation, own breath, or, in more advanced forms of meditation, the present moment). They try to focus on a selected object or activity for a certain period of time. And even if motivation for this training is conditioned by the practitioner's tradition, the moment of concentration on a single object is always present in his exercise. ${ }^{11}$

In the last decades of the 20th century, there were the first attempts to reflect upon the Eastern psychological methods in the social sciences. However, they did not receive much appreciation in practice (probably due to their non-Western epistemological foundation). In spite of this fact, the co-operation of Daniel Goleman (a cognitive-behaviourally oriented author) with Tändzin Gjamccho (the contemporary Dalai Lama), or the comprehensive psycho-therapeutic approach Satitherapy by Czech author Mirko Frýba, who was directly inspired by Hinayan Buddhism, should be mentioned. ${ }^{12}$ Their knowledge of the psychology of human personality is still valid. Using purely empirical Buddhist psychology, they assumed certain hypotheses about the human mind which were recently confirmed by neuroscience research.

One of the most important opinions about the human mind in the area of Buddhist psychology is the assumption that the mindful attention has the fundamental importance when achieving our daily and long-term goals (the feelings of satisfaction in life are directly related to it). In Buddhism, this psychology is associated with the fundamental goals of human life as defined by Gautama Buddha (Siddharta Gautama of the Sakai family). These goals should help one to liberate himself from the cycle of birth. This process is usually prevented by bad behaviour under the influence of passions which attract us and throw us into the repeated 'incarnations'. In order to overcome this problem, one can reflect carefully upon each situation and avoid bad behaviour under the influence of negative emotions. Meditation exercises are an important tool for strengthening this competence.

Apart from these rather exotic worldviews, we can acknowledge the method where one is focused on common and ethically justifiable solutions (without succumbing to strong emotions) as a universally valid way of managing various situations. If we look at the models of applying this idea in practice, we gain a picture of the psychology of successful coping with various situations associated with the risk of succumbing to passion and with the consequent choice of destructive behaviour. ${ }^{13}$ However, even thanks to current neuroscience research in the brain, we know that single-point meditation practice can really affect our ability to act on this idea.

11 Cf. GOLEMAN, Základy meditace...

12 Cf. FRÝBA, Umění žit štastně...; FRÝBA, Psychologie zvládání života...

13 Cf. GOLEMAN, Destruktivní emoce...; Tändzin GJAMCCHO and Howard C. CUTLER, Cesta ke štěstí: Průvodce dobrým životem, Praha: Pragma, 1999. 


\subsection{Mindfulness Training as a Topic of Neuroscience Research}

As stated before, mindfulness training is not conditioned by belief in Buddhism or other religion. ${ }^{14}$ Apart from the cultural context of the conception of this method, one can perceive it only as a behavioural training of conscious attention as we are able to explain and defend its use in practice in direct work with clients thanks to the perspectives of modern neuroscience which are anchored in the tradition of Western science.

According to previous studies of attention which were realised with the help of new imaging methods, some effects of attention training at the level of the neuronal architecture of the brain were manifested by the emergence of new neural connections between individual parts of the brain.

Goleman and Siegel present the conclusions of several studies that mention, in particular, the impact of mindfulness exercises on the following areas of the brain.

1. Strengthening of neuronal systems in the frontal parietal cortex. These systems are responsible for concentration. They allow the transmission and retention of attention when one focuses on the selected objects in one's mind. ${ }^{15}$ Among other things, these neuronal systems play a crucial role in learning processes where the use of focused attention activates nerve impulses in the respective parts of the brain and stimulates the growth of new connections between neurons. ${ }^{16}$

2. Decreased stimulation of the vagus nerve system. The vagus nerve controls some physiological functions that react with increased activity in a stressful situation. The reduced level of stimulation of this nerve helps to maintain a higher degree of deliberation in an emotionally challenging situation. ${ }^{17}$

3. Strengthening the function of mirror neurons. Considering the fact that the neuronal circuits responsible for attention are closely interconnected with the circuits of mirror neurons, empathy, an important component of success in social relationships, is also strengthened. ${ }^{18}$

Structural changes in brain architecture also affect brain functions. According to meditating individuals, strengthening the abovementioned areas of the brain manifests itself through the different intensity of experiencing many mental states and through the development of some mental abilities. In the current literature we can find the conclusions of many studies describing various benefits of regular mindfulness training. For example, Hick presents the following benefits of this exercise: clear awareness of thoughts and emotions; acquiring the ability to approach pain and difficulty in new ways; strengthening the ability to cope with emotional disturbance; development of creative thinking; development of self-awareness and subsequent positive self-perception; greater sense of well-being; the ability to respond to stress more effectively, or the ability to make decisions with greater clarity and awareness. ${ }^{19}$ Other authors, for example, Ellen Langer and Mihnea Moldoveanu, emphasise the effects of mindfulness training on the learning process as mindfulness exercise seems to strengthen our ability to concentrate and it supports memory. ${ }^{20}$ Immune system strengthening, or the reduction of physical impact of stress on the body, are also worth mentioning. ${ }^{21}$

14 Cf. HICK, Mindfulness and Social Work..., p. 3.

15 Cf. GOLEMAN, Pozornost..., p. 202.

16 Cf. Daniel SIEGEL, Vnitřní nazírání, Praha: Triton, 2014, pp. 108-109.

17 Cf. GOLEMAN, Pozornost..., p. 202.

18 Cf. SIEGEL, Vnitřní..., pp. 83, 110.

19 Cf. HICK, Mindfulness and Social Work..., pp. 9-10.

20 Cf. Ellen J. LANGER and Mihnea MOLDOVEANU, The Construct of Mindfulness, Journal of Social Issues 2000/1, pp. 3-4.

21 Cf. Dharma Singh KHALSA, Stress, Meditation, and Alzheimer's Disease Prevention: Where The Evidence Stands, Journal of 
Thanks to these positive effects of mindfulness training practice on the mental fitness of practising people, this method has recently been addressed by many social work professionals who are aware of its positive benefits when working with different client groups. Some of these areas will be discussed in the following chapter. The chapter will also summarise the research that has been carried out in the social work area.

\section{Mindfullness Trainining in Social Work}

Generally speaking, mindfulness training in the area of social work is usually used in situations where the client lacks the competence to regulate some aspects of his behaviour. ${ }^{22}$ In these moments, mindfulness exercises can become a part of the strategy of the entire intervention for the benefit of the client. The aim of this chapter is to present some examples of the use of mindfulness training in selected areas of social work where the conscious attention exercise has been experimentally verified and has produced positive results.

\section{Social Work with Depressed People}

In social work, it was possible, for the first time, to notice the successful use of mindfulness training in cooperation with clients who suffered from depression. Generally, social workers encounter this type of client in their practice quite frequently. Usually, this takes place within various multidisciplinary teams focused on comprehensive rehabilitation of people who are socially affected due to their illness. Social workers can provide them with different types of counselling (individual and family counselling, or crisis intervention) and often can also mobilise different support networks through case management in the client's favour. As part of teamwork, they coordinate their activities with psychiatrists and psychologists who are responsible for pharmacological treatment and psycho-therapeutic care. In addition, they also communicate with the client's family and, if necessary, with his immediate social environment.

The realised research has led to the conclusion that the application of mindfulness training in the field of social work with depressed people is possible and in some ways beneficial. Trained social workers, in collaboration with doctors, can offer clients supportive therapy based on a specific type of mindfulness training which can strengthen the effects of antidepressant treatment and professional psychotherapy well. ${ }^{23}$ In particular, it is an approach developed by Jon Kabat-Zinn. It focuses on the reduction of stress and anxiety ('mindfulness-based stress reduction') and has some proven results in the treatment of depression. Primarily, mindfulness exercise practice has a positive effect on the management of depressive relapses (comparable to antidepressant effects in the maintenance phase of treatment) as it enhances the clients' ability to manage cognitive symptoms of depression such as distorted thinking, concentration difficulties, and memory disorders. Given the fact that these symptoms can disrupt all aspects of clients' lives (including their successful functioning in society), and thus worsen their further condition, it is certainly appropriate (from the point of view of social work) to work on strengthening clients' competences in the area of focused attention. Mindfulness-based methods are proven type of help in this case. ${ }^{24}$

23 Cf. Steven F. HICK and Levia CHAN, Mindfulness-Based Cognitive Therapy for Depression: Effectiveness and Limitations, Social Work in Mental Health 3/2010, pp. 225-237.

24 Cf. Tomoko SUGIURA and Yoshinori SUGIURA, Common Factors of Meditation, Focusing, and Cognitive Behavioral Therapy: Longitudinal Relation of Self-Report Measures to Worry, Depressive, and Obsessive-Compulsive Symptoms Among Nonclinical 


\section{Care for People with Dementia}

Mindfulness training can be a welcome helper in the care of people with dementia. Although dementia is incurable, some of its symptoms can be alleviated or slowed. At the same time, one can think about maintaining an acceptable quality of life for people with this disease. With regard to the fact that dementia causes mainly the decline of cognitive abilities and an increased incidence of negative emotions in the life of such ill individuals, it is precisely mindfulness training which can be considered the most appropriate supportive means as it can suppress the manifestation of some of these symptoms.

The realised research has confirmed the positive effect of mindfulness training on sick people in the area of the prevention of stress conditions. The practitioners reported a reduction in the incidence of accompanying stress symptoms such as anxiety and insomnia. There was also a decrease in the occurrence of inflammation, calcium regulation disorders, cardiovascular diseases including hypertension, and diabetes. ${ }^{25}$ An equally important proven benefit of mindfulness training is also an alleviation of depressive states. It turns out that even people suffering from progressive cognitive decline can still manage their negative emotions with the vigilance, that is, stay away from emerging negative emotions and reorient their attention to more positive mental content. Unconfirmed assumptions include the hypothesis that mindfulness training has a positive effect on memory and cognitive functions in the case of people with dementia (it works the same as with healthy people). Besides the relative improvement of these functions in the event of the elimination of stress and depression through mindfulness training exercises, no study has shown unequivocal confirmation of any effect on reversing or inhibiting the course of the disease as such. Nevertheless, the research on this issue still continues. ${ }^{26}$ As the research dealing with the effects of mindfulness training on the memory of people with mild cognitive impairment suggests, this method could be meaningfully used at least in the early stages of dementia. ${ }^{27}$

\section{Work with Students and Pupils with Learning Disabilities}

In the area of social work focused on children and young people, workers often have to deal with students and pupils with specific learning disabilities. To a greater extent, these individuals experience more anxiety and stress in connection with school in comparison to their peers. This issue often negatively affects their school behaviour and often also their compulsory school attendance. This can also negatively affect their study and social skills improvement. All these factors can reinforce each other, and it is difficult to find a way out of these vicious circles.

In addition to standard social work practices, mindfulness training can play a positive role in the process of addressing these difficulties. This fact is suggested by a pilot study by Beauchemin, Hutchins and Patterson. ${ }^{28}$ It focused on anxiety reduction and social skills strengthening of pupils

Students, Mindfulness 6/2015, p. 619; Tomoko SUGIURA and Yoshinori SUGIURA, Cognitive decentering: Relation to constructs from cognitive behavioral therapy and positive psychology, in: Psychology of Mindfulness, ed. Kimiyo MURATA-SORACI, New York: Nova Science Publishers, 2014, pp. 58-61.

25 Cf. KHALSA, Stress..., pp. 1-12.

26 Cf. () Gina L. HEMMESCH, Exploring the Use of Mindfulness with Individuals Diagnosed with Alzheimer's Disease (on-line), available at: http://sophia.stkate.edu/msw_papers/462, cited $13^{\text {th }}$ October 2018.

27 Cf. ( ) Rebecca Erwin WELLS et al., Meditation's impact on default mode network and hippocampus in mild cognitive impairment: a pilot study (on-line), available at: https://www.ncbi.nlm.nih.gov/pmc/articles/PMC4022038/, cited 13 ${ }^{\text {th }}$ October 2018.

28 Cf. James BEAUCHEMIN, Tiffany L. HUTCHINS and Fiona PATTERSON, Mindfulness Meditation May Lessen Anxiety, Promote Social Skills, and Improve Academic Performance Among Adolescents With Learning Disabilities, Complementary Health Practice Review 1/2008, pp. 34-45. 
with specific learning disabilities through mindfulness training. In line with theoretical expectations, the study confirmed the significant decline in stress levels after five weeks of regular mindfulness practice in a group of 34 monitored high school students who had been diagnosed with learning difficulties. Also, there has been a significant improvement in their social competences as well as in their school performance according to the assessment. These results must be considered preliminary. And even if it is a specific group, there is no reason to believe that its members should respond to mindfulness training differently from a standard population sample as several studies have shown similar effects in the latter case. ${ }^{29}$ Beauchemin, Hutchins, and Patterson's conclusions also support research which was aimed at the reduction of ADHD symptoms through mindfulness training. It was realised by Van der Oord et al. (2012), Weijer-Bergsma et al. (2012), and Herman H. M. Lo et al. (2016). ${ }^{30}$ Given the fact that ADHD and specific learning disabilities often occur together, it can be assumed that various differences in the functioning of the central nervous system of these pupils are not a major obstacle to the use of mindfulness training for the benefit of these children.

\section{Social Work with Drug Users}

Resistance to the short-term needs (and their fulfilment) and their suppression in favour of greater profits in the long run is an ability that substance users do not usually possess to the required extent. Although they are aware of the harmful future consequences of using these substances, they cannot resist the feelings of craving, the attractiveness of such substances. A useful competence in the process of resisting these temptations (and others) is the ability to interrupt the craving process by diverting internal attention away from the object of desire. Attention is then directed somewhere else. ${ }^{31}$ As many studies have shown, mindfulness training is a proven means of strengthening this competence. This can be perceived as a useful tool especially during rehab and further in the context of relapse prevention strategies. ${ }^{32}$

Mindfulness training is particularly effective for clients with the following characteristics: 1 ) users with a deeper degree of addiction, who have good reasons to fear the future negative consequences for health and other impacts of use and are thus motivated to change; 2) at the same time, they are often people who use drugs to cope with certain stress, anxiety or other discomfort in their lives. ${ }^{33}$ Mindfulness training usually helps clients to resist compulsive thoughts connected to drug use during rehab and relapse prevention. A common coping strategy is to strengthen the client's ability

29 Cf. Kimberly A. SCHONERT-REICHL et al., Enhancing Cognitive and Social-Emotional Development Through a Simple-to-Administer Mindfulness-Based School Program for Elementary School Children: A Randomized Controlled Trial, Developmental Psychology 1/2015, pp. 52-66; (C) Charlotte ZENNER, Solveig HERRNLEBEN-KURZ and Harald WALACH, Mindfulness-based interventions in schools - a systematic review and meta-analysis (on-line), available at: https://www.frontiersin.org/articles/10.3389/fpsyg.2014.00603/ full, cited $14^{\text {th }}$ October 2018.

30 Cf. @ Saskia VAN DER OORD, Susan M. BÖGELS and Dorreke PEIJNENBURG, The Effectiveness of Mindfulness Training for Children with ADHD and Mindful Parenting for their Parents (on-line), available at: https://www.ncbi.nlm.nih.gov/pmc/articles/PMC3267931/, cited 14 ${ }^{\text {th }}$ October 2018; (C) Eva van de Weijer-BERGSMA, Anne R. FORMSMA, Esther I. DE BRUIN and Susan M. BÖGELS , The Effectiveness of Mindfulness Training on Behavioral Problems and Attentional Functioning in Adolescents with ADHD (on-line), available at: https://www.ncbi.nlm.nih.gov/pmc/articles/PMC3438398/, cited 14 ${ }^{\text {th }}$ October 2018; $\odot$ Herman H. M. LO et al., The effect of a family-based mindfulness intervention on children with attention deficit and hyperactivity symptoms and their parents: design and rationale for a randomized, controlled clinical trial (study protocol) (on-line), available at: https://www.ncbi.nlm.nih.gov/pmc/articles/ PMC4791862/, cited $14^{\text {th }}$ October 2018.

31 Cf. Walter MISCHEL, Marshmallow test - Jak se naučit sebekontrole, Praha: Ikar, 2015.

32 For an overview of the most important studies on this topic see () Sarah BOWEN and Matthew C. ENKEMA, Relationship between Dispositional Mindfulness and Substance Use: Findings from a Clinical Sample (on-line), available at: https://www.ncbi.nlm.nih.gov/ pmc/articles/PMC3909670/, cited $3^{\text {rd }}$ November 2018. 
to recognise drug craving early. It includes increased attention to the internal (emotional and cognitive) and external (connected to a certain situation) incentives associated with the use of the substance, and the development of certain coping skills (or techniques) for managing such situations. ${ }^{34}$ Obviously, mindfulness training can be a powerful supportive tool in all these processes. Realised research studies confirmed several positive impacts of exercise on the client's abilities. Clients who learned to manipulate their attention better through mindfulness exercise could maintain an indifferent relationship to the substance-related thoughts and feelings better. Thereby, they were able to dampen the escalation of patterns that can lead to drug reuse. These achievements tend to be repeated and create a pattern of behaviour that allows clients to break the 'feedback loop. ${ }^{35}$ Another positive effect of mindfulness training is a decrease in the occurrence of factors which are often associated with relapse, such as anxiety, depression, or stress. These are a common part of our lives in the process of managing a variety of everyday issues. The permanent influence on the ability to self-regulate emotions can reduce the frequency of negative feelings which was previously the active trigger for drug craving. ${ }^{36} \mathrm{New}$ studies have shown that every practising client (regardless of class, ethnic origin, educational attainment, income, or even experience of poverty, homelessness, or violence) has the potential to achieve the above mindfulness training results. ${ }^{37}$

\section{Spiritually Sensitive Social Work}

It is certainly no surprise that mindfulness training has its place in the practice of spiritually sensitive social work. Obviously, due to its origin in the religious systems of the East, and due to its form and many common features with some Western contemplation methods, it is predestined for widespread use within the area of collaboration of social workers and clients from different cultural backgrounds. ${ }^{38}$ Mindfulness exercises are at the heart of a significant number of meditation and contemplation methods of all world religions where these methods are generally recognised as the fundamental pillars of their members' spiritual life. ${ }^{39}$ In the context of spiritually sensitive social work, these traditional methods can be seen as a way to strengthen the client's spiritual competence, i.e., to develop his spiritual life. That is a legitimate goal of cooperation in this approach. ${ }^{40}$ In this case, mindfulness training is not primarily aimed at strengthening the client's individual personal competencies for solving one's personal and interpersonal problems (as is the case of the standard use of 'secular' mindfulness training techniques). On the other hand, these phenomena often appear as side benefits of such practice. ${ }^{41}$

Not all followers of these religions are practising these methods. On the other hand, it is possible to say that, in contrast to the past, active spiritual practice is part of the lives of not only monastic communities but also many lay people. Practising a variety of meditation and contemplation

34 Cf. ( ) Sarah BOWEN et al., Mindfulness-Based Relapse Prevention for Substance Use Disorders: A Pilot Efficacy Trial (on-line), available at: https://www.ncbi.nlm.nih.gov/pmc/articles/PMC3280682/, cited $3^{\text {rd }}$ November 2018.

35 Cf. () Katie WITKIEWITZ et al., Mindfulness-Based Treatment to Prevent Addictive Behavior Relapse: Theoretical Models and Hypothesized Mechanisms of Change (on-line), available at: https://www.ncbi.nlm.nih.gov/pmc/articles/PMC5441879/, cited $3^{\text {rd }}$ November 2018.

36 Cf. @ BOWEN and ENKEMA, Relationship...

37 Cf. () Eric L. GARLAND et al., Mindfulness is Inversely Associated with Alcohol Attentional Bias Among Recovering AlcoholDependent Adults (on-line), available at: https://www.ncbi.nlm.nih.gov/pmc/articles/PMC3532517/, cited $3^{\text {rd }}$ November 2018.

38 Cf. Edmund SHERMAN and Max SIPORIN, Contemplative Theory and Practice for Social Work, Journal of Religion \& Spirituality in Social Work: Social Thought 3/2008, pp. 260-261.

39 Cf. ibid.

40 Cf. ibid., p. 269.

41 Cf. Wilfrid STINISSEN, Křestianská hlubinná meditace, Kostelní Vydř́: Karmelitánské nakladatelství, 2007, p. 14. 
methods is a matter of individual choice of believers. Most churches not only tolerate this fact but also actively support the organisation of various seminars, workshops and spiritual meetings for lay people inside and outside the church, or publish various books and articles on the subject. It is a natural reaction to the findings of psychologists such as John Dewey and Abraham Maslow. Those claim that spirituality is 'a human phenomenon and that it is more basic than and prior to traditional, institutional expressions of religiosity.' ${ }^{42}$

When seeking the client's resources, social workers can appreciate and strengthen the spiritual aspect of his personality. In this particular aspect they can legitimately see a factor which positively affects the client's motivation to change his situation (perceived in the wider context of his life). ${ }^{43}$ Social workers support the client's activities aimed at the development of his spiritual life. These include various meditative exercises which can be found within each religious tradition. ${ }^{44}$ Mindfulness training practice in the form of some traditional meditation or contemplation (in addition to other spiritual methods and techniques) can develop and deepen the awareness of certain 'roots' of one's life in God or more generally (in the case of a non-religious form of spirituality) in Being. ${ }^{45}$ In the context of this process, the perspective of life is gradually changing and new attitudes to the everyday life difficulties are emerging. There is a sense of positive self-confidence, but also confidence in ethically acceptable solutions to one's situations. Relationships with other people, society, and the environment are changing, and motivation to work for their good is emerging. Meditation is thus a 'source' of not only individual work, but eventually also community work aimed at establishing or strengthening social justice for whole groups in society. ${ }^{46}$

Of course, the abovementioned also applies to spiritually sensitive social work in the Christian environment. Christian tradition knows many different contemplative and meditation techniques. We, as social workers, can provide clients with the necessary information and evaluation of their focus. More of them link the contemplation practice with the use of discursive reason, will, emotions, and imagination. ${ }^{47}$ However, there are also techniques that are built on the use and strengthening of conscious attention. These may be suitable for a large number of religious clients, given the current cultural trends. For example, there are John Maine's Christian Meditation, Wilfrid Stinissen's Christian Deep Meditation, as well as many other approaches inspired by popular authors such as Anthony de Mello, Hugo M. Enomiya-Lassalle and Franz Jalics. These techniques are widely popular, and it is possible to expect further growth of interest in these previously forgotten types of contemplative prayers.

If one speaks about the support of techniques which use and strengthen conscious attention (in the context of Christian spiritually sensitive social work), it should be emphasised that, in this context, it is not appropriate to evaluate the results of exercise in any way. The goal of Christian spiritual practice is not some specific measurable benefits (whether one is talking about strengthening the personal competences of the practitioners or achieving certain degrees of spiritual growth known from Eastern spiritual traditions). It is the further deepening of the relationship with God. Although there are several studies on different forms of Christian meditation which evaluate the effects of regular meditation practice in a similar way to studies on more secular

42 SHERMAN and SIPORIN, Contemplative ..., p. 262.

43 Cf. Edward R. CANDA and Leola DYRUD FURMAN, Spiritual Diversity in Social Work Practice: The Heart of Helping, New York: OXFORD University Press, 2010, pp. 244-247.

44 Cf. ibid., pp. 199-200, 330-344.

45 Cf. SHERMAN and SIPORIN, Contemplative..., p. 268.

46 Cf. Dorothee SÖLLE, Mystika a vzdor, Praha: One Woman Press, 2015.

47 Cf. STINISSEN, Křestanská..., p. 13. 
forms of mindfulness training ${ }^{48}$ none of their authors argue that Christian meditation should be practised solely and above all for these benefits. Christian meditation is a kind of prayer and not a technique of personal self-development. And as a Christian prayer, Christian meditation can also have a healing character. ${ }^{49}$ However, such gifts cannot be enforced through exercise.

\section{Side Effects and Potential Risks of Mindfullness Training}

A significant interest of helping professions in the phenomenon of mindfulness training has brought discussions about the effectiveness of this exercise and its possible risks. Critical comments were directed primarily to conceptual and methodological shortcomings of the realised studies and to a certain schematic character of the conclusions. They neglected the fact that each practising individual responds to mindfulness training quite individually. And thus, the mindfulness training may not always be to the benefit of the client. It does not have to bring benefits at all, or, in the worst case, the effects of exercise can even be negative..$^{50}$

So far, the reflection on this subject has brought some insights that need to be taken into account in practice. The first important question for reflection is, for example, why the practice of mindfulness training should be effective in developing a variety of mental competences. Certainly, one can accept the assumption that conscious attention (mindfulness) is an innate human cognitive ability, and its regular application can often be useful. However, the question of how effective mindfulness training is in strengthening this ability still remains. ${ }^{51}$ Will these effects show up in any of our actions requiring focused attention? Is it possible to confirm with certainty that this is not an autotelic exercise where one practises his attention only to cope with the specific requirements of the selected type of mindfulness practice without any overlap in everyday life? Is it realistic to assume that a strong ability to realise the present moment can strengthen our decision not to succumb to a certain tendency in our minds (e.g., compulsion, experience of certain feelings, tendency to cyclical thought, etc.)? Several recent studies show that the previous questions cannot always be answered entirely positively. For example, Farias and Wikholm report on the results of several randomised studies of the use of mindfulness training in the treatment of depression, stress and anxiety. They suggest that, overall, this method is not more effective than other standard approaches. Only slight improvements in depression and anxiety states and very little improvement in stress reduction have been demonstrated. Conversely, it has not been conclusively proven that mindfulness exercises affect other variables such as positive mood, attention, sleep, or substance use. ${ }^{52}$ It turns out that mindfulness training is not a miraculous panacea. Its results are similar to other recognised approaches. On the other hand, it seems that the research carried out often suffers from various possible methodological shortcomings. If the realised studies show different conclusions, careful consideration should be given to the different variables. Questions should be asked whether all respondents practise the same type of mindfulness training (and what kind then?), and about the philosophical or religious background of the technique used, the duration

48 Cf. ( ) Paul FALLER, Is Meditation a Thing for Children? (on-line), available at: https://www.academia.edu/30973806/Is_Meditation_a_ Thing_for_Children, cited $11^{\text {th }}$ March 2019; (C) Jinse Kim, The Efficacy Of Christian Devotional Meditation On Stress, Anxiety, Depression, And Spiritual Health With Korean Adults In The United States: A Randomized Comparative Study (on-line), available at: https://digitalcommons.liberty.edu/cgi/viewcontent.cgi?article=1953\&context=doctoral, cited $11^{\text {th }}$ March 2019.

49 Cf. STINISSEN, Křestanská..., p. 14.

50 Cf. ( ) Miguel FARIAS and Catherine WIKHOLM, Has the science of mindfulness lost its mind? (on-line), available at: https://www.ncbi. nlm.nih.gov/pmc/articles/PMC5353526/, cited $4^{\text {th }}$ December 2018.

51 Cf. ibid.

52 Cf. ibid. 
and frequency of exercise, length of practice, and, ultimately, the formulation of questions related to subtle issues like our mental experience.

There are other critical responses related to the negative experiences with mindfulness training which were not brought up by the first research studies. Recently, however, it has become apparent that some practising people may have experienced these effects. For example, a study by Deane Shapiro on the effects of intensive and long-term mindfulness exercises suggests that as many as $62.9 \%$ of respondents experienced at least one negative effect such as increased anxiety, depression, temporary disorientation after exercise, some distance from other people, or even fully developed psychotic states. ${ }^{53}$ Other observed adverse effects include feelings of depersonalisation, ${ }^{54}$ creation of false memories, ${ }^{55}$ emotional detachment (including even positive emotions), avoiding more demanding thought activities, loss of appetite, insomnia, executive memory disorders $^{56}$ or the unwanted emergence of traumatic memories from the subconscious. ${ }^{57}$ These are rather episodic experiences, usually manageable by the individuals themselves. These individuals usually continue in their exercise as it brings them more positive than negative results. It seems, though, that some caution is appropriate during the mindfulness practice. ${ }^{58}$ People with a tendency to the above experience will certainly be among the clients of social workers. Thus, social workers should be aware of the possible occurrence of these phenomena. If clients are diagnosed with certain mental illnesses, social workers should consult the use of mindfulness practice with clients' physicians. In the case of other clients, they should at least continuously evaluate clients' exercise experience with regard to possible deterioration in some areas of their lives. Of course, it would be ideal if social workers could receive comprehensive accredited training of the mindfulness method for helping professions. They would be then able to recognise imminent risks in time, and manage them therapeutically. However, except for short-term courses, nothing like this is available at the present moment. ${ }^{59}$

\section{Conclusion}

The aim of this paper was to describe the conceptual basics of mindfulness training and to describe the most important proposals of its use in social work. In connection with this goal, the religious roots of this method and the current reflection of mindfulness training from the neuroscience point of view were briefly mentioned. The emphasis was put on the fact that mindfulness training is focused on strengthening the ability of a person to abstain from certain types of behaviour that are not beneficial for him. This focus existed and was at the forefront of the Buddhist tradition of meditation, and it is also a base for today's mindfulness training approaches. Thanks to modern brain imaging methods, we know the areas of neuronal brain architecture which show a strengthening effect of regular mindfulness exercises. We are able to identify some correlation between these effects and subjectively perceived shifts in the development of some behavioural

53 Cf. Deane SHAPIRO, Adverse Effects of Meditation: A Preliminary Investigation of Long-Term Meditators, International Journal of Psychosomatics 39/1992, pp. 64-65.

54 Cf. M. Kathleen B. LUSTYK, Neharika CHAWLA, Roger S. NOLAN and G. Alan MARLATT, Mindfulness Meditation Research: Issues of Participant Screening, Safety Procedures, and Researcher Training, Advances in Mind-Body Medicine 1/2009, pp. 22, 24.

55 Cf. J. David CRESWELL, Mindfulness Interventions, Annual Review of Psychology 1/2017, p. 508.

56 Cf. ( ) Utpal DHOLAKIA, The Little-Known Downsides of Mindfulness Practice (on-line), available at: https://www.psychologytoday. com/us/blog/the-science-behind-behavior/201604/the-little-known-downsides-mindfulness-practice, cited $4^{\text {th }}$ December 2018.

57 Cf. () William VAN GORDON, Edo SHONIN and Javier GARCIA-CAMPAYO, Are there adverse effects associated with mindfulness? (on-line), available at: http://journals.sagepub.com/doi/10.1177/0004867417716309, cited $4^{\text {th }}$ December 2018.

58 Cf. CRESWELL, Mindfulness..., pp. 507-509.

59 Cf. ( FARIAS and WIKHOLM, Has the science... 
self-regulation competences. These were confirmed by practising individuals during the realised research studies.

Most of these competencies can be seen as key to the realisation of desirable changes in the lives of our clients in the context of social work practice. It is therefore understandable that the variants of mindfulness training have been gradually used in the field of social work. This text offered some examples of social work practice with the successful use of mindfulness training. Examples of client groups that may benefit from mindfulness exercises include those with depression, people with dementia, students and pupils with learning disabilities, or substance abuse users. However, there are other areas of social work where mindfulness training is used experimentally, usually with promising results. One can find this information in relevant literature. It can be assumed that this list of different areas of social work will be further expanded in the future. Wherever there is a lack of behavioural self-regulation, some vulnerability to stress, or a lack of empathy towards others (which applies to virtually all fields of case social work), it is legitimate to think of mindfulness training. However, it is also worth remembering the possibilities that mindfulness training offers to social workers themselves. The specific possibilities of mindfulness exercise as a tool for the development of some personal and professional competencies were described on the website of Caritas et veritas (No. 2, year 2017) by Michal Kaczor. He mentions a large number of benefits that social workers can gain when practising mindfulness exercises. ${ }^{60}$ In practice, these positive effects of exercise are usually manifested in the strengthening of the ability to cope with work stress and in the ability to concentrate when working with clients on key or critical points of cooperation. Likewise, mindfulness training can also be useful for informal carers. These, in particular, can be perceived as a group at risk of chronic stress or burnout. Published research studies have confirmed that practising individuals have enhanced their resistance to burnout and, in addition to that, they have reported better relationships with people in their care. ${ }^{61}$

However, the strong advent of methods using mindfulness training in social work must also lead us to some caution in their use in practice. We must maintain a critical stance despite our optimism. At the end of the text there were mentioned some controversial or negative effects of mindfulness exercises which are rare and individual. Still, they have to be taken into account. In practice, therefore, it is always necessary to continuously reflect upon the effects of exercise, i.e, how this practice influences clients' mental experience. First of all, one needs to take into account that mindfulness training may not have any influence on the client's competences in specific cases. One should then be able to respond flexibly by offering other methods. Secondly, one has to take into account the possibility that mindfulness training in some cases causes some unwanted negative mental states. Subsequently, it is necessary to consider which of the exercises can be used therapeutically. In other cases, it is advisable to interrupt or terminate the mindfulness exercise completely.

Research on the use of mindfulness training in helping professions continues. It specifies the application possibilities of this exercise in practice, reflects potential risk factors, and provides further descriptions of the relationship between various processes in the brain and our mental

60 Cf. Michal KACZOR, Všímavost (mindfulness) jako potenciální nástroj rozvoje osobnosti sociálního pracovníka, Caritas et veritas 2/2017, pp. 40-50.

61 Cf. (c) Constance L COOGLE, Kirk Warren BROWN, Jessica M. HELLERSTEIN and Allie RUDOLPH, Mindfulness-Based Alzheimer's Caregiving: A Randomized Controlled Trial: Replication Report (on-line), available at: https://vcoa.chp.vcu.edu/media/ college-of-health-professions/virginia-center-on-aging/pdf/center-reports/aoa_reporting.pdf2016, cited 28 ${ }^{\text {th }}$ December 2018; Dharma Singh KHALSA, Stress, Meditation, and Alzheimer's Disease Prevention: Where The Evidence Stands, Journal of Alzheimer's Disease 1/2015, pp. 1-12; Ken A. PALLER et al., Benefits of Mindfulness Training for Patients With Progressive Cognitive Decline and Their Caregivers, American Journal of Alzheimer's Disease and Other Dementias 3/2014, pp. 257-267. 
experience. It is likely that complex mindfulness training courses will be developed in the near future. These will directly focus on the use of this method in social work. Over time, mindfulness training will become a standard part of the methods of the social work field for many positive reasons.

\section{Contact}

\section{Mgr. Miroslav Kappl, Ph.D.}

University of Hradec Králové

Philosophical Faculty, The Institute of Social Work

Víta Nejedlého 573, 50003 Hradec Králové

miroslav.kappl@uhk.cz 